\title{
Psicologia e Racismo: as Heranças da Clínica Psicológica
}

\author{
Maiara de Souza Benedito ${ }^{1}$ \\ ${ }^{1}$ Universidade de São Paulo, SP, Brasil
}

Maria Inês Assumpção Fernandes ${ }^{1}$

${ }^{1}$ Universidade de São Paulo, SP, Brasil

Resumo: Este artigo resulta de pesquisa que investiga como a raça e o racismo afetam a prática dos psicólogos. A partir de uma leitura histórica da construção do que é ser negro no Brasil, discute-se as formas como a Psicologia pode contribuir para o enfrentamento do sofrimento causado pelo racismo. Apoiada na psicanálise e, mais especificamente, no conceito de alianças inconscientes, tal como formulado por René Kaës, investiga-se como profissionais no campo da clínica psicológica identificam (ou não) problemas relacionados ao racismo ao analisar como atuam diante dessa problemática. As entrevistas abertas, baseadas nos pressupostos de Bleger, foram realizadas com três profissionais que atuam com dispositivos clínicos em serviços públicos e privados na região metropolitana de São Paulo. A partir dos registros, discutiu-se como o racismo é transmitido entre as gerações e como opera na clínica. Identificou-se que o sofrimento se expressa por experiências de incerteza ligadas ao corpo, ao desejo, à capacidade profissional em situações que se relacionam com a discriminação, o preconceito e a inferioridade. Observou-se a ambiguidade na diferenciação entre racismo e outros tipos de preconceitos sociais e se destaca o valor da apropriação histórica para que os fenômenos raciais possam ser compreendidos e superados. Este estudo conclui que a atuação da Psicologia se faz necessária de maneira política e social.

Palavras-chave: Psicologia, Racismo, Transmissão psíquica, Grupos sociais, Clínica.

\section{Psychology and Racism: the Heritage of Clinical Psychology}

\begin{abstract}
This article is the result of a research that investigates how race and racism affect the practice of psychologists. From a historical interpretation of the construction of what means to be a black person in Brazil, we discuss how Psychology can contribute against the suffering caused by racism. Supported by psychoanalysis and, more specifically, the concept of unconscious alliances as formulated by René Kaës, we investigate how professionals of clinical psychology identify (or not) problems related to racism, analyzing how they act when facing this problem. Open interviews based on Bleger's assumptions were conducted with three professionals who work with clinical devices in public and private services in the metropolitan region of São Paulo. The records were used to discuss how racism is transmitted between generations and how it operates in the clinic, and how suffering is expressed by experiences of uncertainty related to the body, desire and professional ability in situations that refer to discrimination, prejudice and inferiority. There is ambiguity in the differentiation between racism and other types of social prejudice, and the value of historical appropriation is emphasized so that racial phenomena can be understood and overcome. This study concludes that the performance of Psychology is necessary politically and socially.
\end{abstract}

Keywords: Psychology, Racism, Psychic transmission, Social groups, Clinic. 


\title{
Psicología y Racismo: la Herencia de la Clínica Psicológica
}

\begin{abstract}
Resumen: Este artículo es el resultado de una investigación que trata cómo la raza y el racismo afectan la práctica de los psicólogos. A partir de una lectura histórica de la construcción de lo que es ser negro en Brasil, discutimos las formas en que la psicología puede contribuir a enfrentar el sufrimiento causado por el racismo. Con el apoyo del psicoanálisis, más específicamente, en el concepto de alianzas inconscientes formulado por René Kaës, investigamos cómo los profesionales en el campo de la clínica psicológica identifican (o no) problemas relacionados con el racismo, analizando cómo actúan frente a ese problema. Las entrevistas abiertas, basadas en los supuestos de Bleger, se realizaron con tres profesionales que trabajan con dispositivos clínicos en servicios públicos y privados en la región metropolitana de São Paulo. De los registros se discutió cómo se transmite el racismo entre generaciones y cómo funciona en la clínica. Se identificó que el sufrimiento se expresa por experiencias de incertidumbre relacionadas con el cuerpo, el deseo, la capacidad profesional en situaciones que se refieren a discriminación, prejuicio e inferioridad. Hay ambigüedad en la diferenciación entre el racismo y otros tipos de prejuicios sociales y se resalta el valor de la apropiación histórica para que los fenómenos raciales puedan ser entendidos y superados. Este estudio concluye que el desempeño de la psicología es necesario política y socialmente.
\end{abstract}

Palabras clave: Psicología, Racismo, Transmisión psíquica, Grupos sociales, Clínica.

\section{Introdução}

Os negros ${ }^{1}$ de diversas regiões da África foram trazidos ao Brasil para trabalhar como escravos, submetidos ao uso de sua força física e obrigados a viver em um continente desconhecido com outros negros de culturas e línguas diferentes, perdendo suas identidades, bem como sua condição de seres humanos. De forma naturalizada, foram tratados como animais e despossuídos de direitos, mesmo após a promulgação da "Lei Áurea", pois a abolição não se preocupou em inseri-los na sociedade como sujeitos de direitos.

Os trabalhos que desenvolviam até então foram ocupados por imigrantes europeus, tidos como competentes e bons trabalhadores. Os negros, considerados o oposto, eram destinados aos trabalhos domésticos em razão da incapacidade que lhes fora atribuída para as demais funções; subalternos, expunham suas vidas ao risco de morte. Por isso, mesmo em liberdade continuaram marginalizados e participando da sociedade na condição de excluídos ou de incluídos marginalmente, numa estrutura social que procurou manter o sistema de desigualdade. A partir dessa perspectiva, compreende-se que o trabalho destinado aos escravos libertos tinha a função social de impedir que saíssem da marginalidade social. "Por isso, rigorosamente falando, não existe exclusão: existe contradição, existem vítimas de processos sociais, políticos e econômicos excludentes..." (Martins, 1997, p.14).

Conforme discute Isildinha B. Nogueira, a libertação não ocorreu de fato já que, apesar de juridicamente os negros não serem mais escravos, ainda eram excluídos dos direitos sociais e invisíveis na sociedade. Os efeitos da escravidão ainda reverberam, conforme aponta a pesquisadora (Nogueira, 1998, p.15):

Desde então, libertados do cativeiro, mas jamais libertos da condição de escravos, de um estigma, os negros têm sofrido toda sorte de discriminação, que tem como base a ideia de serem os negros seres inferiores, portanto não merecedores de possibilidades sociais iguais.

É pertinente mencionar também que, embora coisificados e oprimidos, os negros não passaram pela escravização passivamente. Durante os anos de escravidão no Brasil, criaram estratégias de resistência:

${ }^{1}$ Neste trabalho, adota-se o termo "negro" como categoria analítica oriunda da denominação dada pelos movimentos negros. Esse termo é usado para se referir ao conjunto da população que sofre os efeitos psicossociais do racismo. 
lutaram pelo direito à liberdade e para manifestar sua cultura e suas crenças religiosas; defenderam a família; fingiram-se doentes para não trabalhar; e sabotaram a produção. Nesse sentido, Reis (1983, p.108) afirma que: “... não foi fácil sobreviver, mas para isso foi preciso muita luta. E se viver é lutar, sobreviver e criar uma cultura de expressão de liberdade que a cultura negra possui, é lutar dobrado".

Por isso, entende-se a resistência como marca da condição negra no Brasil que, desde o período da escravização, resiste individual e coletivamente. Individualmente, os negros resistiram de muitas maneiras: fugindo, recusando-se a exercer certas atividades, suicidando-se (as mães escravizadas assassinavam os filhos e depois se suicidavam) e assassinando seus senhores. Coletivamente, os quilombos se formaram como organização de resistência e os mais de 20 jornais escritos por negros entre 1903 e $1963 \mathrm{em}$ São Paulo, outra forma de resistência ainda pouco conhecida. Fica evidente a construção da luta como a condição própria do negro no Brasil; atualmente, as formas de resistência manifestam-se pelo movimento negro, pela cultura, pela arte, pela moda e pela culinária (Bento, 1998; Silva Jr., 1994).

Dessa forma, buscar entender o papel do negro ao longo da história do Brasil é remeter-se a estudos que falam do período em que eram responsabilizados pelos males que atingiam a nação, seja econômica, política, sócio ou culturalmente. Esses problemas eram associados às suas características físicas e mentais, sob o argumento das diferenças biológicas. Os problemas estruturais eram naturalizados como de origem biológica e de tal forma eram caracterizados como mais predispostos às mazelas físicas e mentais, ao crime e à insubordinação. Sob argumentos em defesa da eugenia, os negros também foram excluídos e confinados nos hospitais psiquiátricos e sujeitos a altas taxas de mortalidade sob o pretexto de uma higienização mental.

No século XIX, a Psicologia desenvolvida na Europa foi trazida ao Brasil pelos psiquiatras a fim de naturalizar distúrbios e deficiências de acordo com a aparência física, base ainda para algumas práticas atuais. O objetivo, na época, era excluir aqueles que estavam fora do critério de normalidade, do qual os negros eram a expressão e o grupo majoritário. Foi esse um dos motivos que implicou a grande imigração de europeus ao Brasil e o início da ideologia de branqueamento.
Saber como os negros eram vistos na sociedade torna-se relevante para compreender o caminho percorrido até os dias atuais. É necessário refletir sobre o modo como a sociedade se relaciona com as diferenças que resultam nas desigualdades. Nesta pesquisa, portanto, pautamo-nos pela premissa de Boaventura de Sousa Santos (1999, p. 61) de que "temos que ser iguais sempre que a diferença nos inferioriza; temos o direito a ser diferentes sempre que a igualdade nos descaracteriza".

Para Hasenbalg (1979), a raça pode exercer papéis simbólicos, valorativos e estratificadores em sociedades multirraciais e racistas, como o Brasil. A adoção desse conceito permite a divisão entre classes, na qual o status ideal pertence à classe dominante branca. Essas divisões e suas consequências, o racismo, não são apenas o resultado do processo histórico vivido na escravidão, mas também são frutos de interesses capitalistas e, por isso, são mantidas.

O racismo atua como forma de dominação que considera o grupo dominado inferior ao dominante, permitindo que o segundo grupo tenha privilégios sobre o primeiro. É uma construção social complexa e multideterminada e que permeia as relações pessoais cotidianas e institucionais. É incorporado historicamente. se mantendo por intermédio de sua reprodução nas relações sociais (Costa \& Scarcelli, 2016; Nunes, 2014; Schucman, 2012; Schucman, Nunes, \& Costa, 2015).

Assim, pensar na atuação dos profissionais da Psicologia diante dessa temática acarreta questionamento sobre a forma como se tem discutido e atuado em questões raciais e os sofrimentos por elas originados. Essa consideração respalda a questão que norteia este trabalho e leva a investigar as práticas da Psicologia. Questiona-se como o (des)conhecimento atravessa o nosso fazer e o quanto estamos construindo e desconstruindo ideologias. Na proposta de explorar a clínica psicológica, questiona-se como a prática clínica é atravessada pelas questões raciais, inquerindo-se sobre a presença da problemática racial nos atendimentos e as intervenções dos profissionais diante do sofrimento provocado pelo racismo.

\section{Justificativa}

Há momentos importantes da Psicologia no que se refere à discussão racial. Conforme apontado por Santos, Schucman e Martins (2012), durante os primeiros anos da vigência de pressupostos da Psicologia 
(no Brasil, muito se associou a raça às patologias psiquiátricas e às tipologias criminais,

No entanto, um segundo momento da Psicologia caracterizou-se por uma mudança radical de pensamento a partir de estudiosos como Virgínia Leone Bicudo, Aniela Ginsberg e Dante Moreira Leite, que consideravam que as diferenças entre as raças abrangiam aspectos econômicos, sociais e educacionais, negando a ideia de investigar determinações genéticas que pudessem causar tais diferenças (Santos, Schucman, \& Martins, 2012).

Já o terceiro momento, marcado pelos estudos de Jurandir Freire Costa, Maria Aparecida Bento e Edith Piza, entendeu raça como construção social e, por meio do estudo das relações de poder, lançaram luz também sob processos de hierarquização e dominação na sociedade (Santos, Schucman, \& Martins, 2012).

Salienta-se que os estudos de Maria Aparecida Bento e Edith Piza foram responsáveis por uma virada de pensamento, no qual o foco deixa de ser o negro e passa a ser as discussões sobre branquitude, o branco como referencial ideal. Branquitude diz respeito a pensar sobre o que significa ser branco em uma sociedade racializada e os lugares estruturais nela configurados, como as representações de cada grupo racial. Outro conceito aprofundado nessa fase foi o de branqueamento, compreendido como um processo pelo qual os negros devem se adequar a uma sociedade branca e consequentemente distanciarem-se e negar sua racialidade (Bento, 2014; Piza, 2014).

Ainda que se reconheça a importância dos trabalhos realizados nos três momentos delineados acima, continua sendo notória a falta de estudos que contemplem os problemas raciais e falem sobre racismo. Seja em razão de a maioria dos profissionais da área ser branca, não ter compreensão do que é raça e acreditar que a branquitude é o padrão de identidade normativo, seja pela dificuldade em reconhecer privilégios dentro de uma estrutura social racista (Schucman, 2014), fica evidente que ainda é pequeno o número de discussões acadêmicas sobre as questões mencionadas. Santos (2011), ao pesquisar diretórios de grupos de estudo sobre programas de ação afirmativa no ensino superior público cadastrados até dezembro de 2007, revelou que apenas 29 entre 20.460 grupos de pesquisa dedicam-se ao estudo de temáticas relacionadas à população negra. De acordo com o autor, os grupos de pesquisa constituem um segmento privilegiado de exercício de poder, já que são capazes de produzir conhecimentos que podem contribuir para construção de políticas que transformam a sociedade e seu futuro.

No sentido de investigar as produções acadêmicas acerca das relações étnico-raciais, o estudo de caráter exploratório realizado por Martins, Santos e Colosso (2013) buscou artigos com foco no tema, publicados entre os anos 2000 e 2009 nos periódicos digitais indexados na Scientific Electronic Library Online (SciELO) e na Literatura Latino-Americana e do Caribe em Ciências da Saúde (Lilacs), encontrando o total de 41 artigos no campo da Psicologia. A área que mais produziu conhecimento sobre o tema foi a Psicologia Social, com 16 artigos. Segundo os pesquisadores, a Psicologia pode contribuir significativamente para a luta antirracista por meio da construção do conhecimento sobre o preconceito e o racismo, da busca por transformar esses processos e da formação dos profissionais para trabalhar com tais questões.

Reconhece-se, aqui, a contribuição e a importância dos trabalhos apresentados anteriormente, destacando-se a necessidade de que o tema continue em discussão e que a produção de conhecimento acadêmico seja ampliada por pesquisadores de todas as áreas, inclusive da Psicologia. Assim, dada a revisão de literatura e a relevância do tema, o objetivo é apresentar a investigação de como os psicólogos compreendem o racismo e a maneira como as questões relacionadas a ele podem atravessar a prática profissional.

\section{Fundamentos teóricos e método}

A vertente da psicanálise que pensa o sujeito como sujeito do grupo, ou seja, constituído nos vínculos intersubjetivos foi desenvolvida pelo psicanalista francês René Kaës (1993, 1997), cuja obra - iniciada na década de setenta do século passado - tem inspirado pesquisas sobre o sujeito do inconsciente como o sujeito do grupo. Segundo Fernandes (2005, p. 128), Kaës propõe em realidade a construção de uma nova metapsicologia, cujo objetivo seria a articulação das relações entre o duplo limite constitutivo do espaço psíquico, descrito por A. Green: o limite intrapsíquico entre o inconsciente e o pré-consciente/consciente e o limite interpsíquico entre sujeito (si mesmo) e não-sujeito. A discussão envolve uma densa questão, à medida que esses dois limites se cruzam dentro e fora de cada sujeito e que a textura psíquica da intersubjetividade é a condição do sujeito do inconsciente. 
O enfrentamento dessa questão implica a construção de novos conceitos. O conceito de aliança procura dar conta da formação do inconsciente no vínculo intersubjetivo e dos processos de transmissão psíquica. As alianças inconscientes reúnem, sob essa denominação, os acordos inconscientes estabelecidos entre vários sujeitos.

Os pactos narcísicos, os pactos denegativos, as alianças denegadoras, a comunidade de negação, o contrato narcísico (Aulagnier, 1979), são manifestações dessas alianças. Elas têm uma tópica e se situam nos pontos de amarração dos vínculos que sustentam os sujeitos singulares e os conjuntos dos quais eles são a parte constituída e a parte constituinte (Fernandes, 2005, p. 129).

Portanto, as alianças inconscientes sustentam a vida psíquica; não pertencem ao sujeito ou ao grupo, mas sim ao vínculo entre eles. São elas que ligam e sustentam os psiquismos de cada membro de um grupo e que permitem, pelo vínculo, o processo de transmissão.

Trabalha-se com a hipótese de que o racismo é expressão de uma aliança inconsciente com a finalidade de perpetuar a dominação de um grupo sobre outro, garantindo que os negros sejam inferiores. Como expressão de uma aliança inconsciente, o racismo é transmitido intergeracionalmente e validado nos vínculos estabelecidos nos grupos. Para que esse tipo de transmissão possa ser transformado, é necessário operar, isto é, trabalhar sobre essas formações psíquicas a fim de que novas ligações sejam possíveis na constituição dos vínculos: formações que sejam sensíveis às transformações e ao reconhecimento da diferença. Como destaca Fernandes (2005, p. 142): “o que está em jogo é a nossa capacidade para reconhecer a diferença e torná-la presente no viver". Pensar o racismo nessas concepções nada mais é do que buscar, por meio da cultura, romper a ideia do negro inferiorizado intelectual e fisicamente. É necessário superar a crença de que os negros são uma ameaça ao desenvolvimento da sociedade e é essencial transmitir para as próximas gerações a noção de que ameaçador é viver em uma sociedade na qual as diferenças, de quaisquer ordens, não permitem o acesso aos direitos civis.

Operando com o método psicanalítico, nesta investigação determinou-se como procedimento de pesquisa a entrevista. Foram realizadas entrevistas com três psicólogas, brancas ou negras, que atuam em atendimentos no contexto da clínica nos serviços públicos e privados da região metropolitana de São Paulo.

A ideia de realizar a pesquisa com profissionais brancase negras vaiao encontro do artigo “White", escrito por Dryer (1988), no qual se faz uma crítica aos estudos que investigam apenas as minorias e, dessa forma, contribuem para que elas permaneçam à margem. Sob essa mesma perspectiva, autoras como Bento e Carone (2014) e Piza (2014) defendem que a compreensão de racismo não se dará com estudos que consideram apenas os negros; é preciso analisar também o papel do branco em sua legitimação e manutenção.

O critério para classificar a raça das profissionais foi feito de acordo com a hetero e a autodeclaração. As entrevistas tiveram embasamento teórico nos pressupostos de Bleger (1980, p. 6), que compreende a entrevista psicológica como "uma relação com características particulares, que se estabelece entre duas ou mais pessoas". A escolha pela entrevista aberta foi feita em razão de sua flexibilidade e da possibilidade da investigação ser configurada pelo próprio entrevistado, podendo ser mais ampla e profunda, conforme definição de Bleger (1980). A pergunta norteadora da entrevista era: "como as questões raciais se expressam no campo da clínica e no dispositivo utilizado?”.

\section{Discussão}

O material, resultado das entrevistas, mostra a complexidade da atividade clínica. Neste artigo discutiremos as questões de maior impacto, considerando-se o referencial teórico acima exposto; referindo-se aos conceitos de transmissão psíquica e alianças inconscientes, buscou-se demonstrar como, pelas alianças estabelecidas nos grupos, ocorre a transmissão, em negativo, de conteúdo das estereotipias e estigmas depositados nas pessoas negras, que implicam em traumas e sentimentos de inferioridade, na ambivalência entre desejo e culpa e em sofrimentos na representação de seu corpo.

Apoiada nas alianças, a transmissão diz respeito ao que é passado de geração em geração, como os valores e crenças conscientemente transmitidos. Contudo, ressalta-se que a transmissão também é marcada pelo negativo, ou seja, por aquilo que não pode ser elaborado por uma geração e é transmitido para a seguinte, de forma inconsciente, sem um trabalho psíquico. Isso quer dizer que o que foi impossível 
de ser simbolizado numa geração chega à outra em estado bruto, sem o trabalho simbólico, ou seja, sem o trabalho do pensar.

Então você começa a buscar as coisas, começa a investigar, começa a ir atrás e aí você vê que vem de outras gerações, que vem essa questão. "Ai, meu cabelo é ruim". "É ruim por quê?". "Ele te fez maldade?". Né? Então são termos e coisas que as pessoas usam e nem percebem que elas mesmas estão passando para a frente a questão do racismo (J., entrevista 1).

A atribuição do adjetivo "ruim" ao cabelo crespo é algo naturalizado no vocabulário do senso comum; porém, resta a dúvida se as pessoas saberiam responder por que acreditam nisso. Certamente, este é um discurso que ouviram uma vez e passaram a reproduzi-lo ou, como a ideia que esta discussão propõe, a desqualificação do cabelo crespo e das demais características físicas dos negros foi transmitida por gerações.

Como temos afirmado, as transmissões acontecem por meio de alianças inconscientes, formações psíquicas intersubjetivas que são construídas por sujeitos vinculados entre si, para reforçar e manter certas funções e estruturas que garantem o vínculo. Fernandes (2005) explica que essas são expressões de acordos coletivos. A mestiçagem, como exemplo, tem sido uma ideologia garantida por esses acordos. Para a autora, a mestiçagemé uma herança transmitida entre gerações que expressa a história dos povos brasileiros. Cabe elucidar que a mestiçagem, aqui retratada, fala de um apagamento da diferença. Pensar a mestiçagem, dessa forma, é compreendê-la como a ideologia que permite a manutenção de determinadas estruturas sociais quando elas estão ameaçadas. A ideologia permite a continuidade e, a partir da racionalização, impede que a diferença se manifeste, como sublinha Fernandes (2005, p. 139): "A mestiçagem cruza fronteiras. Mas a diferença está no coração da formação da cultura, como elemento essencial".

Há muitas diferenças na sociedade brasileira, porém nem todas estão marcadas pelos atributos anteriormente apresentados. Dessa forma, outro aspecto observado é o da ambiguidade, isto é, a dificuldade da diferenciação do racismo de outros tipos de preconceito. Em relação à maneira como o racismo se expressa no dispositivo clínico utilizado, uma entrevistada afirma que:
Vêm pela queixa, principalmente das crianças, com a questão do bullying. E aparece, sobretudo, não só racial, mas pela forma do corpo. Então se a pessoa é gordinha, e por aí vai. Mas costuma aparecer sim, e não só nas crianças, mas em adultos e adolescentes também. Sempre questão da baixa autoestima, sabe? De bullying, dessas coisas assim. Aparecem bem (J., entrevista 1).

Diferentemente do bullying, definido como a violência no contexto escolar baseada no preconceito e cometida frequentemente por alunos mais velhos ou fisicamente mais fortes a um mesmo aluno (Antunes \& Zuin, 2008; Crochík, 2012), o racismo inferioriza o negro em sua totalidade e não permite a ele existir enquanto sujeito de direitos e potencialidades. É importante considerar que o racismo é uma ideologia e uma aliança na qual se mantém a ideia de uma hierarquia racial e seus privilégios. Colocar o racismo no mesmo pé de igualdade que determinadas manifestações de violência é desconsiderar que aquelas situações que geram violência são contingenciais e podem acometer qualquer pessoa. Salienta-se a especificidade do racismo, que apresenta um viés ideológico sustentado pela crença de que os negros são inferiores.

Parte-se então para o próximo ponto manifesto nas entrevistas: a questão da diferença como inferioridade. Como acima afirmado, o racismo diferencia-se de outros preconceitos. Sustentado pela crença de que os negros são inferiores, está diretamente relacionado ao lugar que lhes é dado socialmente. A discriminação é apenas uma das formas de expressão do racismo; já o racismo é parte da própria estrutura social. "Eu sofria, é claro, todos nós sofremos racismo, seja por um gesto ou uma expressão de palavra ou atitude de um racismo institucional" (O., entrevista 2).

O lugar de inferioridade é determinante de insegurança e sofrimento. Há constantes dúvidas e dificuldades em fazer um alinhavo entre ser negro e ser capaz.

As angústias produzidas pelos estereótipos que o racismo produz de inferioridade, de não saber se dar conta, de se apropriar, de não saber identificar seus atributos, competências, as dificuldades de colocá-los em prova.... Porque, às vezes, há uma dúvida: "Sou capaz mesmo? Não sou capaz, né?" (V., entrevista 3). 
Existe o sentimento de ser uma farsa, de estar usurpando uma posição na qual não se deveria estar:

Ela usa essa expressão: "eu sou uma farsa". Por que uma farsa? Ainda que os efeitos psicossociais do racismo (que é com o que eu lido) ainda estejam tão enraizados nela que, mesmo que ela seja uma profissional que fale outra língua, que esteja trabalhando em uma multinacional, a sensação de incapacidade, de não acreditar na própria inteligência ainda é grande, mesmo com todas essas conquistas (O., entrevista 2 ).

Como essas decorrências do racismo não existem sem estarem acompanhadas de tantas outras, as dificuldades de compreender quem se é e de aceitar suas próprias características podem causar muito sofrimento. Psicologicamente, isso é imensurável, mas fisicamente é possível dimensionar a partir do preço a ser pago no corpo quando se busca alcançar uma beleza distinta daquela que lhe é natural.

Algumas pessoas acham que cabelo é só estética, cabelo não é só estética porque cabelo historicamente... nosso cabelo, historicamente, tem sido um elemento de sofrimento, porque a gente quer ter cabelo liso, mas, felizmente, cada vez menos. Mas o cabelo compõe a nossa apresentação e, durante muito, muito, tempo foi muito difícil para a gente se apresentar com nosso cabelo natural e a gente precisou usar de instrumentos de tortura para o nosso cabelo ficar liso. Eé uma tortura porque: orelha queimada, testa queimada, couro cabeludo queimado, e isso é um instrumento de tortura $(\mathrm{V}$, entrevista 3$)$.

Sim, desejei ter cabelo liso, brincava com a toalha na cabeça para balançar. Tive muita testa e orelha queimada, deixei de ir em muitos lugares porque tomei chuva e não podia ir mais para o baile, porque o cabelo tinha voltado ao normal. Sofrimento, isso é motivo de sofrimento ( $\mathrm{V}$, entrevista 3$)$.

Para Nogueira (2017), a procura pela inalcançável brancura surge como uma possibilidade de participar do mundo que transcende às falhas do branco, visto pela perspectiva do negro oprimido. Para ele, o corpo é motivo de sofrimento e objeto de negação. Mais uma vez, temos um exemplo ilustrativo: "Então essa questão, assim, de querer pintar o cabelo de loiro e lisinho, sabe? Com chapinha e coisa assim, quer dizer, a pessoa.... É como se fosse uma negação da raça" (J., entrevista, 01).

Partindo da compreensão de que o sujeito é constituído pelo olhar do outro e considerando que esse outro enxerga o corpo negro como inaceitável, feio, insuficiente, sujo e outros adjetivos pejorativos, Nogueira (1998, p. 91) expõe que: "resta ao negro, para além de seus fantasmas, inerentes ao ser humano, o desejo de recusar esse significante, que apresenta o significado que ele tenta negar, negando-se a si mesmo pela negação do corpo".

Assim, não é preciso ressaltar que, em todos os aspectos mencionados, o sofrimento é inerente. Nos relacionamentos afetivos das vítimas de racismo não é diferente, pois se identifica a contradição entre o desejo e a culpa de se relacionar com uma pessoa pertencente à raça diferente.

E também aparece, algumas vezes, os desejos não confessáveis, né?!... Desejo pelo homem branco... No que se refere às mulheres, não veem como um desejo, mas veem como uma atração, uma... Um ataque a si, uma culpa, muitas vezes de não dar conta de responder ao racismo que vai vivendo no cotidiano. Que vai vivendo seja por opção, seja por medo de que venha um ataque ainda maior. Seja por medo de não ter argumento, recursos internos suficientes, para dar conta dessas discriminações percebidas. Seja... vem também... o medo às vezes, de inquirir o outro, de responder o outro. $O$ medo de que isso vá trazer algum prejuízo na sua jornada, trajetória. De maneira geral, é isso que vem. Vem também... as contradições quando você, quando a família é inter-racial. Vem as contradições de afeto: "Se eu gosto de um, não devo gostar do outro? Como eu devo gostar do outro?". Isso no caso das mais ativistas, mais politizadas (V., entrevista 3).

Para entender a razão de a culpa estar presente nos relacionamentos afetivos das mulheres negras com os homens brancos, é necessário, ao menos, passar pela questão da solidão da mulher negra. Sucintamente, as mulheres negras, como todas as mulheres, podem enfrentar muitos obstáculos para estar em relacionamentos afetivos; somadas às dificuldades, está o marcador da raça, que potencializa 
que sejam consideradas a última das opções de escolha dos homens brancos e negros.

bell hooks (1993/2000) chama a atenção para o fato de que, na vida dessas mulheres, há pouco ou nenhum amor; esse sofrimento é tão doloroso que permanece privado, oculto dos espaços públicos. Se antes, em virtude de tantas violências, as mulheres negras não tinham a possibilidade de pensar no direito de amar e ser amada, agora essa realidade tem sido debatida. Discutem-se os privilégios dos homens negros, que são vítimas do racismo, mas não são atravessados pelo machismo e, por isso, ainda podem escolher com quem se relacionar e, em sua maioria, escolhem construir suas famílias com mulheres brancas, o que está diretamente relacionado a sair do lugar de inferioridade, sobretudo depois de ascender socialmente.

É a "palmitagem": um neologismo usado para expressar a relação de pessoas negras com pessoas brancas. Embora tenha sido criado para fazer a crítica aos homens negros que desconsideram as mulheres negras nas escolhas afetivas, dando preferência a mulheres brancas, o termo também tem sido utilizado para provocação de mulheres negras que se relacionam com homens brancos. Contrário às relações inter-raciais, há dentro do movimento negro quem defenda que o amor deve ser afrocentrado e que a relação entre negros também se constitui um ato político (Carneiro, 2002; Moutinho, Alves, \& Mateuzi, 2016). São pontos para mostrar as contradições de uma mulher negra politizada em desejar estar com um homem branco.

Os conflitos não se restringem aos relacionamentos afetivos sexuais. Há aqueles vivenciados dentro da própria família, que nem sempre acompanha os passos e os pensamentos advindos da militância.

Como fazer o enfrentamento ao racismo se eu tenho um pai branco, se eu tenho uma mãe branca? A ambiguidade de pais de casamentos inter-raciais: a ambiguidade primeiro de poder reconhecer se aquilo é racismo ou não é racismo. $E$, no reconhecimento, uma dificuldade de poder lidar, de poder enfrentar. Porque uma coisa é enfrentar o vizinho, outra coisa é enfrentar o pai, enfrentar a mãe e dizer: "você é racista". O que significa isso? E também as dores de viver o racismo dentro de casa: de não ser reconhecido, de ser motivo de chacota (V., entrevista 3 ).
A dificuldade em se localizar e se apresentar em sua identidade não aparece só dentro da família, mas também no restante da sociedade. Há uma problemática do lugar, dos lugares que estão sendo transmitidos pela condição do racismo: o de subalternos e subordinados.

Uma delas, por exemplo, quando o chefe (no caso o presidente da empresa, trabalha numa multinacional), às vezes, se aproxima dela, ela quer sumir. Ela mesma diz: "eu quero sumir, eu não quero que ele me veja ou fique claro que ele vá achar que eu sou uma farsa... . Então, fazer um trabalho para que ela possa sair desse casulo em que foi envolvida, de que ela não tem capacidade, não é inteligente, não é bonita, está sendo um processo.... Está sendo um processo. E não é da noite para o dia, né? Então, basicamente, fora o cansaço físico, dor nas costas, dor de cabeça, tensão mandibular de ter que usar placa, dificuldade de ter que enfrentar determinados lugares, os chamados redutos brancos. Ou seja, alguns restaurantes ou mesmo bairros, algumas lojas. Agora, isso com o processo terapêutico tem diminuído, mas isso também é uma das questões trazidas aqui no consultório (O., entrevista 2).

As dificuldades observadas podem estar associadas ao constatado sequestro da história do sujeito, cometido pelo eurocentrismo que, apossado da história africana dos negros, impediu que esta fosse disseminada fidedignamente.

Nãofaz a crítica que a Europa, de alguma maneira, como colonizadora, foi a sequestradora de praticamente todos os povos. Sequestrou bens, bens intelectuais, bens materiais. Se se pensar no Egito, por exemplo, que não se reconhece como um Egito negro, isso é fruto do eurocentrismo. "Como que os negros podem construir pirâmides?”. Quer dizer, é sequestrar uma parte da história, para que você não atribua àquele grupo, que você acha menor, a capacidade cognitiva, intelectiva, de pensamento e de construção. Então é preciso retirar dos povos que foram colonizados a sua capacidade criativa e científica. Isso a Europa fez com todos os grupos, com todos no continente africano, está explícito que ela fez. Ela também fez isso com outros grupos raciais, para hoje, por exemplo, tem 
muita gente que acredita que o berço da humanidade seja a Europa. Então eu preciso restituir. Se a gente pensar que Picasso bebeu em África, mas que não citou a fonte: é isso. Isso é um sequestro. Ele pode ser maravilhoso agora, ele é mais maravilhoso do que os artistas africanos? De reinos antigos, de descobrimentos que até hoje vigoram na humanidade? (V., entrevista 3).

O impedimento de acessar as origens e percorrer trajetórias dignas e respeitosas a partir delas é mais uma das sequelas do processo de branqueamento, como registra Francisco Weffort, citado por Santana (2015): "o branqueamento apaga as glórias dos negros, a memória dos líderes que poderiam sugerir caminhos diferentes daquele da humilhação cotidiana, especialmente dos pobres". Ademais, o eurocentrismo e a branquitude não só recusam que os negros pensem a própria história, como também não se enxergam como parte dela.

Pessoas brancas não pensam nas questões raciais. Nunca. Isso não existe. Não existe. Para eles não existe [risos]. Quem traz essa temática são as pessoas negras, de diversos tons de pele. A pessoa branca não traz essa questão, não traz (O., entrevista 2).

A falta de debates é o que mantém as estruturas racistas. $\mathrm{O}$ silêncio não mobiliza, ele cristaliza.

É um silêncio estratégico, né?! Não é um silêncio comum, mas é um silêncio de quem tem dificuldade para lidar com isso, de alguém que não conhece a história, que vai ter que se ver porque a questão racial diz respeito a todos nós, ele vai ter que se ver consigo mesmo também. Vai vero quanto a pessoa também está implicada nisso, então é difícil, mas a gente tem cavado espaços, dando visibilidade. As redes sociais têm um papel extremamente importante nesse sentido, de dar visibilidade a essa temática. E o racismo está saindo da toca, né? Esse racismo cordial, cada vez mais a gente vê, principalmente as celebridades que dão mais notoriedade para isso. Quando aparece a questão racial. Nós, reles mortais, vamos viver o sofrimento no dia a dia, mas cada um vai buscando uma forma de mudança disso. Seja na militância, seja no ativismo, sendo formador de opinião, sendo uma professora, como também estudando para fazer mudança desse pensamento nas pessoas, né? Aprender a ver as pessoas dessa forma é cômodo, porque tem privilégios, ninguém quer sair desse lugar: tem medo. As pessoas têm muito medo, acham que vão perder os privilégios, $e$ as pessoas ainda pensam sobre isso, mas isso também é um outro recurso (O., entrevista 2).

As relações afetivas, familiares e sociais e os lugares simbólicos são pautados pelo racismo, não sendo diferente dos lugares geográficos, os territórios negros são pouco privilegiados socialmente, com restrições de acesso a serviços como saúde, educação e segurança e discriminados pela pobreza; mesmo quando localizados em regiões nobres, os únicos olhares percebidos são os de incômodo.

... vários elementos vão compondo a sua condição de sujeito, né? O país que você mora, a região, se ele foi um país colonizado ou colonizador... Uma coisa é nascer no Brasil, outra é nascer na Suécia, portanto, isso já dá uma condição de quem eu sou, uma coisa no Brasil, São Paulo, vai que está mais perto de nós: uma coisa é ser filho do Morumbi, da parte rica do Morumbi, e outra coisa é você nascer no Capão Redondo, né? Então, o território é um elemento importante, que entra na configuração da nossa história. Porque, se eu nasci no Capão, já desde muito cedo vou me deparar com violências, com precariedades, precariedades de todos os níveis. No serviço público, na escola, na saúde, na assistência. Se eu estou no Morumbi, eu vou ter grandes escolas, vou ter um serviço público de qualidade. Então, assim, pensar o racismo também pensar é em como é que ele se materializa no território. Porque se eu estou na Brasilândia ou se eu estou no Capão Redondo e eu estou no CAPS, eu preciso saber que ali é um território negro e, se ele é um território negro, é um território que está assediado pela violência policial o tempo todo. E se, portanto, eu sou negra e se eu estou no território, eu também sou alvo, assim como os moradores do território (V., entrevista 3).

Prioritariamente, nesta investigação, aborda-se os atendimentos da psicologia clínica públicos ou privados. Contudo, é relevante salientar que essas reflexões não se limitam a esses dispositivos de 
atendimento. De fato, a clínica não corresponde apenas a uma única forma de atuação em um espaço delimitado pelo enquadre; mas, faz referência ao posicionamento dos psicólogos perante às relações com os outros e com o mundo e é sustentada pela escuta, que pode ser exercida para além das salas e consultórios de análise e psicoterapia (Garcia, 1997; Levy, 2001).

Dito isso, admite-se a existência de estruturantes psíquicos responsáveis pelo delineamento do sofrimento de ser negro. Não se pode deixar de sê-lo, por mais que sejam feitas infindáveis tentativas.

Mas é importante que eu pense isso dentro de marcadores estruturais. Eu não posso pensar, por exemplo, que ser gordo é a mesma coisa do que ser negro. Porque ser negro é um elemento estruturador da condição do sujeito. Ser gordo não é um elemento estruturador, é um elemento que vem com o tempo e que pode ir embora com o tempo, né? Aquilo não é: eu não posso deixar de ser negra, jamais. Eu continuarei sendo mesmo que eu não queira. E eu serei tratada, mesmo que eu não goste (V., entrevista 3).

Se não se pode abandonar a negritude, tampouco é possível fazê-lo com suas representações sociais e estereótipos.

Eu acho... eu acho que assim, junto com a raça, está muito ligada, está muito relacionada a questão da pobreza, a questão da escravidão, sabe? De injustiça após injustiça, não sei o que, não sei o que... toda essa discrepância, né? Que a gente tem socioeconômica mesmo. Então eu vejo que as pessoas não se veem negras, porque "ai, vão dizer que eu sou pobre", alguma coisa mais ou menos nesse estilo, eu acho. Acho que está muito associado (J., entrevista 1).

Na dimensão clínica, em psicologia, há um espaço para elaboração que pode auxiliar a iniciar-se e permanecer na luta pelo reconhecimento de si próprio. Essas elaborações devem considerar o âmbito pessoal e ser inseridas no contexto histórico, como ilustrou uma das profissionais entrevistadas:

Portanto, é necessário que a gente possa, obviamente, com as ferramentas da Psicologia e da Psicanálise, introduzir o sujeito na história do seu grupo, para que ele possa construir uma história de si articulada. Ele precisa saber que o que está acontecendo com ele é um ataque ao seu grupo, não é um ataque a ele. Até porque o sujeito nem conhece ele.... "Vai me atacar por quê? É a primeira vez que me viu, está atacando ao meu grupo através de mim". Isso resolve? Isso elimina a humilhação? Não, não elimina. Não elimina a humilhação, porque o sujeito está ali sendo alvo de uma violência, mas, se ele está integrado na história, pode responder de uma forma diferenciada, e não necessariamente carregar culpa (V., entrevista 3 ).

Estar atento a como os negros são vistos enquanto grupo é importante para fazer essas elaborações, pois, como disse Schwarcz em debate com Conte e Kon (Conte, Schwarcz, \& Kon 2015, p. 113): ao olhar para o passado, é possível se dar conta do quanto ele faz parte do presente. Nessa perspectiva, fica mais fácil de compreender as palavras de Gonçalves Filho (1998, p.148).

O racismo é, eminentemente, um fenômeno histórico, e os fenômenos históricos são eminentemente sociais. É uma luta de grupo contra grupo. A humilhação de um negro é praticada de modo nunca destinado a apenas a ele. $\mathrm{O}$ ataque a "um negro" é sempre um ataque "aos negros". $\mathrm{O}$ ataque racista deve valer a muitos, a todos os negros. É um ataque exemplar, contra um grupo, e que representa os interesses do grupo atacante.

O valor de respeitar o sujeito enquanto um sujeito está fundamentado acima da análise sobre a raça. Por isso, o olhar para a questão da raça e do racismo é fundamental, mas o olhar para o sujeito em si é imprescindível, a fim de não negligenciar quaisquer questões que sejam inerentes a um sujeito. Isso é visível nas seguintes palavras:

Porque o sujeito que vem para análise é uma pessoa. Como diz James: "foi o branco que me nomeou de negro, se não fosse isso eu seria apenas uma pessoa". Eu acho que poder olhar: "é verdade, o racismo me atravessa desde antes de eu nascer e não termina depois que eu morrer. Mas eu também carrego outras questões próprias de ser humano!". Então é preciso que a gente possa reconhecer isso, distinguir porque senão o sujeito entra na minha sala e eu fico esperando as experiências 
de racismo, e deixo de reconhecer as experiências que aquele humano que está na minha frente vive: que podem ser iguais a de qualquer humano, de qualquer raça e etnia (V., entrevista 3 ).

Esse movimento, como profissional, muitas vezes requer o olhar para si mesmo enquanto sujeito singular:

Sei lá, acho que, para você ser um psicólogo, tem que rever todos os seus valores. Porque senão é aquela história: "eu não gosto de gays". Então como você vai tratar uma pessoa que vem com toda uma questão sexual, de identidade e tal? Você não gosta. "Então eu tenho que pôr uma plaquinha no meu consultório: não atendo no meu consultório gays, lésbicas e transexuais". Fica difícil, aí a gente revê tudo isso na faculdade. Logo no comecinho, pelo menos na faculdade que eu fiz, a gente teve esses questionamentos e tal. Para a gente tentar rever os nossos valores e ver se realmente a gente tem alguma coisa assim, algum preconceito com relação a alguma coisa e rever isso, né? O ruim é a gente negar que tem (J., entrevista 1 ).

Nota-se que, para não prosseguir sendo encarado como um problema só dos negros, é necessário fazer parcerias com aqueles que podem não experimentar as mesmas dores, mas tem a capacidade de sensibilizar-se a elas:

Nós não mudamos só mudando o negro. Nós temos que mudar a sociedade. A sociedade é composta de brancos, negros, indígenas, de amarelos.... O branco precisa saber o que é branquitude. Ele é racializado, é preciso que ele seja... que ele tenha a consciência de que é racializado. E do que significa ser racializado para ele e para nós. É preciso uma conversação. A radicalidade não ajuda. E porque falar para nós é importante, porque é do jeito que a gente vai se construindo e se constituindo de uma forma positiva. Mas nós temos também que falar para o outro, porque nós não existimos só entre nós.

Tudo isso é luta. De negros e de parceiros. É preciso reconhecer a existência de parceiros brancos. Porque eles estão na direção, se você não tem parceria com eles você vai demorar muito tempo.... E porque eles são parte do problema, não só por- que eles estão. É porque eles são parte do problema. E porque eles são parte do problema, eles também são parte da solução. Por isso, nós não podemos falar só para nós: temos que criar alianças, alianças importantes, alianças fortes (V., entrevista 3 ).

A maneira como essas parcerias podem ser construídas se dá pela tentativa de tornar compreensível as dores provocadas pelo racismo; aproximando-se das dores vivenciadas pelas pessoas que não são negras, não para mensurar, mas para se fazer compreender. Pois, imensurável que é, quem já sentiu dor, sabe o que é doer.

Mas o fato de eu ser branco não significa que eu não saiba o que é humilhação, porque, em algum momento na vida qualquer pessoa, branco, negro, amarelo, indígena, seja lá o que for, viveu uma humilhação na vida e, muitas vezes, tão violenta quanto é a violência do racismo. Então todos nós sabemos o que é viver uma humilhação. (V., entrevista 3).

A humilhação adotada nessa interpretação é a humilhação social (Gonçalves Filho, 1998), na qual o humilhado é impedido de ter reconhecida a sua humanidade. É amparada na angústia da desigualdade. Então, quem já esteve no lugar de desigual, pode ter sido humilhado e saber como é. Porém, após a dor manifesta, ela pode ser elaborada, no sentido de mostrar a sua especificidade, ou seja, como é diferenciada de outras dores:

A diferença da humilhação para brancos e negros é que negros vivem humilhação cotidianamente. O negro é forjado na humilhação, porque o racismo está aí, todo dia e toda hora. Muitas vezes, eu posso nem me dar conta (V., entrevista 3).

Reconhece-se a necessidade de uma apropriação histórica, para que os fenômenos raciais possam ser compreendidos e superados não só na clínica psicológica, mas também na sociedade em sua totalidade, tanto por negros quanto por brancos. Essa herança é de todos, como apontam as ricas contribuições dadas pelas psicólogas entrevistadas:

Todos nós estamos implicados. Porque a literatura fica fracionada, ela traz uma gama de questões. 
Se não trata outra questão.... Nos cursos, nos livros de Psicologia, trata como se todo mundo fosse igual, né? Somos iguais, mas a dinâmica psíquica, por conta do envolvimento social, é diferente. Freud já dizia: "nós somos atravessados pela nossa cultura". Se, na cultura, é tratado de uma questão de todo mundo ter privilégios, todo mundo tem igualdade, isso também.... O branco e o negro sofrem com isso. As empresas não sabem lidar com a diversidade, elas têm prejuízos com isso, perdem oportunidades. O país perde oportunidades, o país perde talentos e por aí vai.... Todos nós perdemos. A história é deles também.... É se apropriar da história, isso é para brancos e negros. Porque se nós temos a herança da escravização, os brancos têm a herança do senhor escravo. É a história deles, quando o branco se apropriar da história efetivamente, ele pode fazer uma crítica à Psicologia e compreender que é preciso que ele faça uma Psicologia diferenciada. Porque ele também tem uma herança e a dele não é uma boa herança (V., entrevista 3$)$.

Por fim, pensar os dispositivos clínicos como espaços possíveis ao enfrentamento do racismo demanda que esse seja um trabalho localizado numa zona intermediária entre o social e o clínico. Trabalho que é atravessado não só pelo processo de racialização de quem é atendido, mas pela própria identidade racial de cada profissional. No caso de uma das profissionais entrevistadas, observa-se em seu espaço de análise as dificuldades de interpretação a respeito de sua negritude por parte de seu terapeuta, uma vez que este manteve-se no espaço da clínica e talvez tenha deixado de visitar o social ou, ainda, tenha visitado o social pelo lugar que lhe é de herança: o da branquitude.

Pesquisadora: Mas você já percebia que aparecia essa temática?

O: Sim. Desde a primeira vez quando eu fiz terapia. Teve uma cena que até hoje eu não esqueço. Eu não tinha noção do que eu estava falando, eu não tinha muita clareza do que eu estava falando. Hoje, eu tenho mais clareza do que aconteceu. A primeira vez quando eu fui fazer terapia, falei para o meu terapeuta, perguntei se ele gostava de chocolate ao leite. Ele é psicanalista, ele não sacou o que eu disse, mas estava dito que era preto com branco, eu sou uma pessoa miscigenada. Até hoje, não houve resposta. Ele disse que gostava, passou, mas ele não aprofundou essa questão.

Pesquisadora: Não entendeu o que você queria trazer pra ele...

O: Sim. Estava no meu inconsciente, se ele tivesse manejo disso: pronto, né? A minha trajetória mesmo, de lidar com essa questão, de outras vezes que eu sofri racismo, estaria muito melhor para tratar o racismo que eu vivi. Mas não houve isso (O., entrevista 2).

\section{Considerações finais}

Ao longo dos dois anos do desenvolvimento desta pesquisa, houve uma construção contínua sobre o tema e a ampliação dos dados empíricos sobre psicólogas que trabalham com a temática racial foi muito enriquecedor. Essa mudança permitiu o reconhecimento de diversos temas e conceitos pertinentes ao trabalho da Psicologia referente às relações raciais, transformando os resultados de uma discussão que, por vezes, é interpretada como previsível ("precisamos discutir racismo na Psicologia") em dados de pesquisa inovadores.

Observou-se, neste estudo, que o racismo é sinônimo de sofrimento e que não há aspectos da vida dos negros que não estejam atravessados por ele de maneira direta ou indireta. A dificuldade de reconhecê-lo como expressão de uma violência distinta de outras favorece sua perpetuação.

O racismo caminha ao lado do verbo "viver", como uma companhia que até pode fechar os olhos, mas nunca dorme. Permanece como herança, passada de geração em geração e transmitida pelas alianças contraídas no seio de grupos sociais.

No que concerne à Psicologia, ainda que avanços significativos tenham sido reconhecidos sobre esta densa questão, faz-se mais do que necessário haver uma contínua reflexão com vistas a um processo de elaboração que permita a abertura de um novo caminho que leve a uma transformação dessa herança. Isso requer uma aproximação da problemática racial e dos traços históricos contextualizados no país, com o intuito de compreender seus atravessamentos no psiquismo. Conforme Borges 
(2017) citando Kon explica, o trauma do Brasil com relação às dores de sua colonização e escravatura é uma conta que se mantém aberta.

Retomando o objetivo deste trabalho de investigar como raça e racismo afetam a prática dos psicólogos, é possível perceber que essa relação carece da dimensão histórica. Identificou-se que, somente a partir e por meio dessa apropriação da história, a Psicologia poderá contribuir com toda sua potência de agente de transformação para a questão do racismo.

Mostra-se essencial que a Psicologia, enquanto ciência e profissão, compreenda os fenômenos psíquicos a partir das questões apresentadas nas singularidades dos sujeitos. Contudo, entendendo-se a constituição subjetiva como produzida nos vínculos sociais e grupais, essa singularidade só será escutada se contemplarmos as vicissitudes de sua relação a estruturas sociais.

A partir da compreensão do sujeito enquanto sujeito do vínculo e do grupo, uma investigação dos processos intersubjetivos que se manifestam nos grupos permitiria o acesso a outro entendimento dos processos psicossociais e sócio-históricos (Fernandes \& Scarcelli, 2017), como tessitura da transmissão. Dessa forma, é importante, no contexto da clínica, estar atento não somente a uma visão patologizante de problemas tidos como singulares ou individuais, pertencentes somente a um sujeito isoladamente; na verdade estamos diante de um problema que exige um olhar e uma escuta às dimensões social e política (Fernandes, 1999).

Os registros das entrevistas mostram que essas conexões são necessárias para sua atuação. Defende-se que se a graduação em Psicologia não forneceu ou não fornece as ferramentas para lidar com o sofrimento causado pelo racismo, fazendo-se imprescindível a constante busca por tal conhecimento em outros espaços e campos do saber: na história, na sociologia, nas artes e na política. De outro lado, os registros mostram também as dificuldades no enfrentamento do racismo pela psicologia, quando se revela a falta de recursos e estudos que identifiquem um caminho e as consequências dessa situação em termos de resistência ao processo: "algumas coisas não se discutem".

É muito comum surgir tal situação. Quando iniciado qualquer questionamento acerca do racismo, ele é comparado a outras opressões consideradas mais relevantes: a homofobia, o machismo e a divisão de classes ou comparado a ter uma doença terminal ou lhe faltar um membro. Há que se considerar que uma pessoa pode ser mulher, ser negra, ser lésbica e estar com HIV ou câncer. Na verdade, todas as opressões causam sofrimento e exigem consideração. Nas palavras de Audre Lorde (2009, p. 220), a respeito da ausência de hierarquia de opressão:

Eu não posso me dar ao luxo de lutar por uma forma de opressão apenas. Não posso me permitir acreditar que ser livre de intolerância é um direito de um grupo particular. E eu não posso tomar a liberdade de escolher entre as frentes nas quais devo batalhar contra essas forças de discriminação, onde quer que elas apareçam para me destruir. E quando elas aparecem para me destruir, não demorará muito a aparecerem para destruir você.

Deve-se considerar que a profissão se apoia em um Código de Ética e de atuação profissional que exige posturas que se oponham às violências e visem transformações que emergem do âmbito pessoal e alcançam a sociedade como um todo. Percebe-se que por parte das psicólogas negras e dos psicólogos negros há uma evidente procura por instrumentos que possibilitem falar de raça, racismo e suas implicações em suas práticas profissionais. Da negritude não se foge, na Psicologia ou em qualquer profissão. Não é uma opção. E ser psicóloga negra ou psicólogo negro significa se deparar-se com essa falta de recursos.

Encontrar armas para lutar contra o racismo é uma responsabilidade profissional, social, política, histórica e afetiva. Por outro lado, a acomodação de muitos profissionais é uma demonstração de que a branquitude não se mobiliza para discutir a questão do racismo. A possibilidade de abordá-lo implica numa ação profissional e política fundamental a fim de que se encontrem caminhos de ruptura dessas alianças inconscientes, pactos denegativos que impedem a interpelação da própria branquitude e a transformação das formas contratuais dos vínculos de opressão e violência. Enriquecendo-se desse debate, a Psicologia pode contribuir para construções acadêmico-profissionais, históricas, sociais e políticas inovadoras. 


\section{Referências}

Antunes, D. C., \& Zuin, A. A. S. (2008). Do bullying ao preconceito: os desafios da barbárie à educação. Psicologia \& Sociedade, 1(20), 16-32. https://doi.org/10.1590/S0102-71822008000100004.

Bento, M. A. S. (1998). Cidadania em preto e branco: discutindo relações raciais. Ática.

Bento, M. A. S., \& Carone, I. (2014) (Orgs.). Psicologia social do racismo (6a ed.). Vozes

Bento, M. A. S. (2014). Branqueamento e branquitude no Brasil. In M. A. S. Bento, \& I. Carone (Orgs.). Psicologia social do racismo (6 ${ }^{\mathrm{a}}$ ed., pp. 25-58). Vozes.

Bleger, J. (1980). Temas de Psicologia: Entrevistas e Grupos. Martins Fontes.

Borges, R. (2017). Prefácio. In N. M. Kon, M. L. Silva, \& C. C. Abud (Orgs.). O racismo e o negro no Brasil: questões para a psicanálise (pp. 07-14). Perspectiva.

Carneiro, S. (2002). Gênero e raça. In C. Bruschini, \& S. G. Unberhaum (Orgs.). Gênero, democracia e sociedade brasileira (pp. 167-194). Fundação Carlos Chagas.

Conte, B. S., Schwarcz, L. M., Silva, M. L., \& Kon, N. M. (2015). Racismo, este estranho familiar. Percurso, 54(28). http://revistapercurso.uol.com.br/index.php?apg=artigo_view\&ida=1176\&ori=edicao\&id_edicao=54.

Costa, E. S., \& Scarcelli, I. R. (2016). Psicologia, política pública para a população quilombola e racismo. Psicologia USP, 2(27), 357-366. https://doi.org/10.1590/0103-656420130051.

Crochík, J. L. (2012). Fatores psicológicos e sociais associados ao Bullying. Psicologia Política, 24(12), 211-229.

Dryer, R. (1988). White. Routledge.

Fernandes, M.I. A. (1999). Saúde mental: a clausura de um conceito. Revista USP,43, 90-99. https://doi.org/10.11606/ issn.2316-9036.v0i43p90-99.

Fernandes, M. I. A. (2005). Negatividade e vínculo: a mestiçagem como ideologia. Casa do Psicólogo.

Fernandes, M. I. A., \& Scarcelli, I. R. (2017). A queda do hífen: história, política e clínica. In N. da Silva Junior, \&W. Zangari (Orgs.). A psicologia social e a questão do hífen: Programa de Psicologia Social do Instituto de Psicologia da Universidade de São Paulo (pp. 103-116). Blucher.

Garcia, C. (1997). Clínica do Social. UFMG.

Gonçalves Filho, J. M. (1998). Humilhação Social: um problema político em psicologia. Psicologia USP, 2(9), 11-67. https://doi.org/10.1590/S0103-65641998000200002.

Hasenbalg, A. (1979). Discriminação e desigualdades raciais no Brasil. Graal.

hooks, b. (2000). Living to Love. In M. Plott, \& L. Umansky (Orgs.). Making Sense of Women's Lives: an Introduction to Women's Studies. Rowman \& Littlefield. (Original publicado em 1993).

Kaës, R. (1993). Transmission de la vie psychique entre les générations (em Le sujet de l’heritáge). Dunod.

Kaës, R. (1997). O grupo e o sujeito do grupo: elementos para uma teoria psicanalítica do grupo. Casa do Psicólogo.

Levy, A. (2001). Ciências clínicas e organizações sociais: sentido e crise do sentido. Autêntica.

Lorde, A. (2009). There is no hierarchy of oppression. In R.P. Byrd, J. B. Cole, \& B. J. Sheftall. I Am Your Sister (pp. 219-220). Oxford University.

Martins, J. S. (1997). Exclusão social e a nova desigualdade (3a ed.). Paulus.

Martins, E., Santos, A. O., \& Colosso, M. (2013). Relações étnico-raciais e psicologia: publicações em periódicos da SciELO e Lilacs. Psicologia: Teoria e Prática, 3(15) 118-133.

Moutinho, L., Alves, V., \& Mateuzi, M. (2016). Quanto mais você nega, mais eu me reafirmo: visibilidade e afetos na cena periférica paulistana. Tomo, 28, 265-291.

Nogueira, I. B. (1998). Significações do corpo negro [Tese de doutorado não publicada]. Instituto de Psicologia, Universidade de São Paulo.

Nogueira, I. B. (2017). Cor e Inconsciente. In N. M. Kon, M. L. Silva, \& C. C. Abud (Orgs.). O racismo e o negro no Brasil: questões para a psicanálise (pp. 121-126). Perspectiva. http://dedalus.usp.br/F/ FJG1N9FAAA2G5HPSQQ69E87YV4YIT7TA26XRHB3N5MA1GU1X4R-38289?func=full-set-set\&set_number= 004199\&set_entry $=000005 \&$ format $=999$ 
Nunes, S. S. (2014). Racismo Contra Negros: sutileza e persistência. Psicologia Política, 29(14), 101-121.

Piza, E (2014). Porta de vidro: uma entrada para branquitude. In M. A. S. Bento, \& I. Carone (Orgs.). Psicologia social do racismo (pp. 59-90). Vozes.

Reis, J. J. (1983). Resistência Escrava na Bahia. "Poderemos Brincar, Folgar e Cantar...": O Protesto Escravo na América. Afro-Ásia, 14, 107-123.

Santana, B. (2015). Quando me descobri negra. Sesi-SP Editora.

Santos, A. O. (2011). Panorama dos programas de ação afirmativa para inserção da população negra no ensino público superior brasileiro (2002-2007): estudos e grupos de pesquisa. Revista da ABPN, 5(2), 99-114.

Santos, A. O., Schucman, L. V., \& Martins, H. V. (2012). Breve histórico do pensamento psicológico brasileiro sobre relações étnico-raciais. Psicologia: Ciência e Profissão, esp(32), 166-175.

Santos, B. S. (1999). A construção multicultural da igualdade e da diferença. Oficina do CES, Centro de Estudos Sociais (pp. 1-63). Universidade de Coimbra.

Schucman, L. V. (2012). Entre o "encardido", o "branco" e o "branquíssimo": raça, hierarquia e poder na construção da branquitude paulistana [Tese de doutorado. Instituto de Psicologia da Universidade de São Paulo]. Biblioteca Digital Teses e Dissertações USP. https://www.teses.usp.br/teses/disponiveis/47/47134/tde-21052012-154521/ pt-br.php.

Schucman, L. V., Nunes, S. S., \& Costa, E. S. (2015). A Psicologia da Universidade de São Paulo e as relações raciais: perspectivas emergentes. Psicologia USP, 1(28), 144-158. https://doi.org/10.1590/0103-6564a20132413.

Silva Jr., H. (1994). Direitos Civis E Relações Raciais No Brasil. Luam.

\section{Maiara de Souza Benedito}

Mestre em Psicologia Social pelo Programa de Pós-Graduação em Psicologia Social do Instituto de Psicologia da Universidade de São Paulo, São Paulo - SP. Brasil.

E-mail: maiarabenedito@usp.br

(1) https://orcid.org/0000-0001-7110-020X

Maria Inês Assumpção Fernandes

Professora titular no Departamento de Psicologia Social e do Trabalho no Instituto de Psicologia da Universidade de São Paulo, São Paulo - SP. Brasil.

E-mail: marines@usp.br

(1) http://orcid.org/0000-0001-5221-8691

Agradecemos à Coordenação de Aperfeiçoamento de Pessoal de Nível Superior (CAPES) pelo financiamento da pesquisa da qual resultou nesse artigo.

Endereço para envio de correspondência:

Universidade de São Paulo, Instituto de Psicologia. Av. Prof. Mello de Moraes 1721, Cidade Universitária.

CEP: 05508-900. São Paulo - SP. Brasil.

Recebido 14/10/2019

Aceito 17/10/2019

Received 10/14/2019

Approved 10/17/2019

Recibido 14/10/2019

Aceptado 17/10/2019 
Psicologia: Ciência e Profissão 2020 v. 40 (n.spe), e229997, 1-16.

Como citar: Benedito, M. S., \& Fernandes, M. I. A. Psicologia e Racismo: as Heranças da Clínica Psicológica. Psicologia: Ciência e Profissão, 40 (n.spe), 1-16. https://doi.org/10.1590/1982-3703003229997

How to cite: Benedito, M. S., \& Fernandes, M. I. A. Psychology and Racism: the Heritage of Clinical Psychology. Psicologia: Ciência e Profissão, 40 (n.spe), 1-16. https://doi.org/10.1590/1982-3703003229997

Cómo citar: Benedito, M. S., \& Fernandes, M. I. A. Psicología y Racismo: la Herencia de la Clínica Psicológica. Psicologia: Ciência e Profissão, 40 (n.spe),1-16. https://doi.org/10.1590/1982-3703003229997 